\title{
REVIEW
}

\section{The role of bronchodilator treatment in the prevention of exacerbations of COPD}

\author{
Jadwiga A. Wedzicha*, Marc Decramer* and Terence A.R. Seemungal"
}

ABSTRACT: Exacerbations of chronic obstructive pulmonary disease (COPD) are natural events in the progression of the disease, and are characterised by acute worsening of symptoms, especially dyspnoea. These heterogeneous events follow increased airway inflammation, often due to infection, and lead to decreased airflow and increased lung hyperinflation relative to stable COPD. Although exacerbation frequency generally increases as COPD progresses, some patients experience frequent exacerbations ( $\geqslant 2$ per year) independently of disease severity. Exacerbations, especially frequent exacerbations, are associated with impaired health-related quality of life, reduced physical activity and poor disease prognosis.

The cornerstone of pharmacotherapy for stable COPD is long-acting bronchodilators, including the long-acting $\beta_{2}$-agonists (LABAs) and long-acting anti-muscarinic agents (LAMAs) alone or combined with inhaled corticosteroids (ICS). While ICS treatment can potentially reduce the risk of exacerbations, clinical studies have demonstrated the efficacy of LABAs and LAMAs in reducing COPD symptoms, primarily by reducing lung hyperinflation secondary to reduced airway resistance. Sustained reduction in lung hyperinflation may in turn lessen dyspnoea during an exacerbation. Indeed, recent studies suggest that bronchodilators may also reduce the incidence of, or prevent, exacerbations.

Using data from recent studies, this review explores the evidence and possible mechanisms through which bronchodilators may prevent exacerbations.

KEYWORDS: Bronchodilator, chronic obstructive pulmonary disease, dyspnoea, exacerbations, long-acting anti-muscarinic agent, long-acting $\beta_{2}$-agonists

hronic obstructive pulmonary disease (COPD) is predicted to become the third most frequent cause of death globally by 2030, and currently affects more than 80 million people worldwide [1]. The most characteristic symptoms of COPD are chronic and progressive dyspnoea, cough and sputum production [2], with dyspnoea usually being the most prominent and distressing symptom [3]. The main pathophysiological features of COPD are expiratory airflow limitation and air trapping, which manifest as lung hyperinflation and dynamic lung hyperinflation during increased ventilation $[3,4]$. This lung hyperinflation contributes to the dyspnoea and resultant activity limitations during stable disease, as well as the acute worsening of symptoms that occur during exacerbations. As COPD progresses, the severity of dyspnoea as well as the severity and frequency of exacerbations increase, leading to a reduction in patients' daily activities and healthrelated quality of life (HRQoL) [2, 4, 5].
Exacerbations of COPD cause a more rapid decline in lung function [6] and result in increased mortality and hospital admissions [5], with associated increases in healthcare resource utilisation and cost $[7,8]$. According to the National Institute for Health and Clinical Excellence (NICE) guidelines in 2010, COPD was the second largest cause of emergency admission in the UK, with one in eight emergency admissions to hospital resulting from COPD, accounting for more than $£ 800$ million in direct healthcare costs [9]. The most recent Global Initiative for Chronic Obstructive Lung Disease (GOLD) guidelines have, therefore, highlighted the importance of treating exacerbations effectively and preventing future exacerbations [2].

Pharmacological management of moderate and more severe, stable COPD is centred on long-acting bronchodilators, which include two classes of drugs, the long-acting $\beta_{2}$-agonists (LABAs) and

\section{AFFILIATIONS}

*Centre for Respiratory Medicine University College London, London,

\#Respiratory Division, University Hospitals, Leuven, Belgium. -Dept of Clinical Medical Sciences, Faculty of Medical Sciences, University of the West Indies, St Augustine Campus, St Augustine, Trinidad and Tobago.

CORRESPONDENCE

J.A. Wedzicha

Centre for Respiratory Medicine, University College London

Royal Free Campus

Rowland Hill Street

Hampstead

NW3 2PF

London

UK

E-mail: w.wedzicha@ucl.ac.uk

Received:

March 222012

Accepted after revision:

July 132012

First published online:

July 262012

This article was modified in April 2016 to correct errors in the licence information. 
the long-acting anti-muscarinics (LAMAs) [2, 9]. Patients with severe COPD who experience repeated exacerbations despite maintenance therapy with a bronchodilator would usually receive an inhaled corticosteroid (ICS), specifically for the management of exacerbations [2]. ICS treatment can potentially reduce the risk of exacerbations [10]; however, there is now increasing evidence from large clinical studies that treatment with long-acting bronchodilators also has a beneficial effect on exacerbations [11-14]. It has also been argued that the bronchodilator component of fixed combinations of ICS and LABAs contributes substantially to their effect on exacerbations [11-15].

In this review, we will consider the evidence for a preventative effect of long-acting bronchodilator treatment on COPD exacerbations, and explore possible mechanisms for such an effect, using data from these recent large clinical studies.

\section{EXACERBATIONS OF COPD}

\section{Aetiology and epidemiology}

Increased obstruction of the small airways and worsening lung hyperinflation during COPD exacerbations is associated with increased airway inflammation and systemic inflammation, compared with stable COPD [4, 16-18]. Furthermore, patients with more severe COPD demonstrate greater increases in airway and systemic inflammation during exacerbations than those with milder COPD, indicating that baseline severity of COPD is predictive of exacerbation severity [19].

COPD exacerbations are heterogeneous events caused by complex interactions between the host, respiratory viruses, airway bacteria and environmental pollution, which lead to an increase in the inflammatory burden [5]. In general, viral and bacterial infections are the most important triggers of exacerbations [2022]. Respiratory bacteria and viruses often act in combination, and have a synergistic inflammatory effect in COPD exacerbations $[5,19]$. Co-infection with viruses and bacteria has been detected in $25 \%$ of exacerbations and is associated with more severe functional impairment and longer hospitalisations [23]. However, in approximately one-third of severe exacerbations a specific aetiology cannot be identified $[2,20]$.

Although exacerbations generally become more frequent and more severe as COPD progresses, a specific phenotype of patients experience a high frequency of exacerbations independent of disease severity [24]. Indeed, a history of frequent exacerbations is often the best predictor of future exacerbations, with patients having consistent exacerbation frequencies when studied from year to year [24-26]. There is evidence that an initial exacerbation increases susceptibility to a subsequent one; hence exacerbations tend to occur in temporal clusters [27, 28]. The high-risk period for recurrence was shown to be within 8 weeks after the initial exacerbation.

Until recently, few studies had investigated the pattern of onset of COPD exacerbations. Using data from daily symptom diaries of 212 patients with COPD, it has now been shown that COPD exacerbations exhibit two distinct patterns, sudden onset and gradual onset (fig. 1) and that these two types were found to be predictive of subsequent clinical outcomes [29].

Sudden onset exacerbations (exacerbation threshold crossed on the same day the symptoms started) were associated with significantly more respiratory symptoms than gradual onset

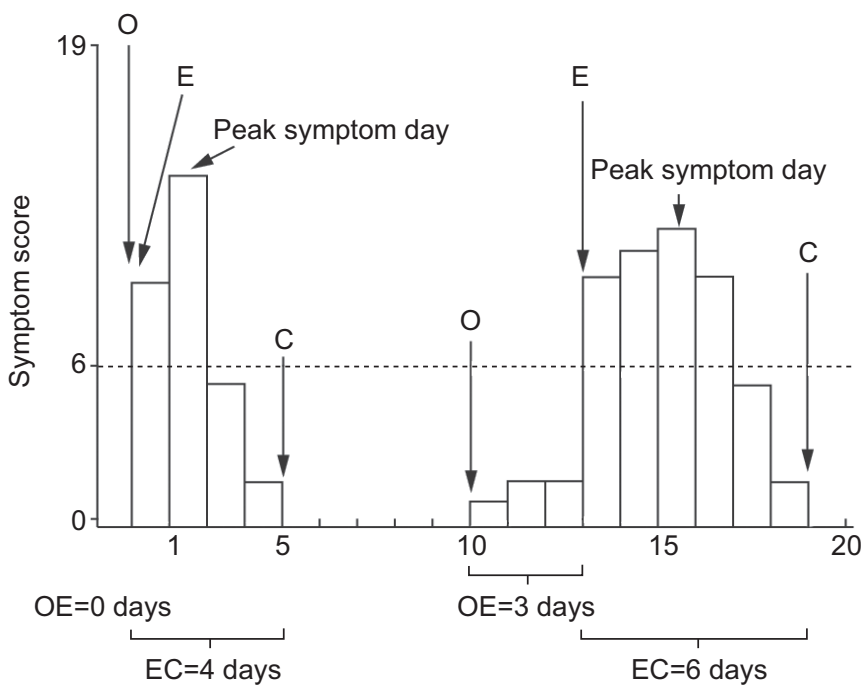

Time days

FIGURE 1. Time course and calculation of the onset and duration of exacerbation (E) intervals: a sudden onset exacerbation is shown on the left $(1,115(56 \%)$ out of 1,995 exacerbation events) and a gradual onset exacerbation is shown on the right (888 (44\%) out of 1,995 exacerbation events). The opening event (O) was defined as the first day of a worsening of respiratory symptoms above usual baseline values (i.e. a daily symptom score $\geqslant 1$ ). An exacerbation was defined as the first of at least two consecutive days on which the patient recorded at least two new or worsening symptoms, at least one of which was a major symptom (i.e. a daily symptom score of $\geqslant 6$ points for two consecutive days). Closing $(C)$ was defined as the first of five consecutive days in which symptoms had returned to their usual baseline levels. The dotted line indicates the exacerbation threshold. OE: number of days between an opening event and the first day of the exacerbation event. Reproduced from [29].

exacerbations (exacerbation threshold crossed $\geqslant 1$ day after symptoms started; $\mathrm{p}<0.001$ ) [29]. However, patients with sudden onset exacerbations experienced a significantly shorter recovery time than patients with gradual onset exacerbations $(\mathrm{p}<0.001)$, which the investigators considered clinically important. This study also showed that in most cases, worsening of respiratory symptoms resolved spontaneously and did not result in an exacerbation [29].

Despite the worsening of symptoms and significant reduction in quality of life associated with exacerbations, as many as $50 \%$ of exacerbations go unreported $[26,30]$. This may reflect patients with COPD just accepting their condition and/or being accustomed to symptom fluctuation as the disease progresses [26]. Identification and education of patients who delay or fail to seek treatment for exacerbations might increase and improve the rate of exacerbation reporting, and reduce patient morbidity and the substantial burden of in-patient treatment of exacerbations on healthcare services [31].

\section{Pathophysiology of exacerbations}

Although the mechanisms involved in exacerbations of COPD are still not fully established, they involve an amplified inflammatory response $[16,19,23]$. These increases in airway inflammation during an exacerbation result in increased ventilation/perfusion imbalance, leading to worsening hyperinflation, dyspnoea, hypoxaemia and hypercapnia in more 
severe COPD [32]. It has also been hypothesised that increased local expression of pro-inflammatory cytokines observed in the external intercostal muscles of patients with COPD may contribute to respiratory muscle dysfunction [33], potentially having a progressively detrimental impact as ventilatory demands increase, such as during a COPD exacerbation.

The progression of stable COPD is characterised by increased numbers of CD8+ lymphocytes, macrophages and neutrophils in the bronchial mucosa [34]. This pattern of inflammation changes during an exacerbation to predominantly neutrophilic inflammation [18, 23]. Furthermore, the clinical severity and inflammatory responses in COPD exacerbations are modulated by the nature of the infecting organism, with bacterial and viral pathogens interacting to cause additional rises in inflammatory markers and greater exacerbation severity $[19,35]$. Sputum and peripheral blood neutrophils have been shown to be significantly increased in all exacerbations, regardless of aetiology, compared with levels during stable convalescence $(\mathrm{p}<0.001$ for both) [23]. The increase in sputum neutrophils was also directly related to exacerbation severity $(p<0.01)$.

Although traditionally viewed as a neutrophil-predominant inflammatory response, eosinophilic airway inflammation also plays a role in exacerbations of COPD $[36,37]$. In a study of 82 patients with COPD, treatment to reduce eosinophilic airway inflammation was associated with a significant reduction in the frequency of COPD exacerbations requiring hospital admission [37]. In particular, an increase in sputum eosinophils has been detected in exacerbations associated with viral infections, but their role as biomarkers for viral exacerbations either in the presence or absence of a bacterial co-infection has yet to be confirmed $[23,38]$.

\section{Clinical consequences of exacerbations}

It is well established that severe exacerbations of COPD requiring hospitalisation are associated with high in-hospital mortality, with one meta-analysis citing an average in-hospital mortality rate of $6.7 \%$ [39]. However, it has been shown that the critical period for mortality exceeds the duration of hospitalisation, increasing the estimated overall average case fatality rate for severe exacerbation resulting in hospitalisation to $15.6 \%$ [39].

Exacerbations (especially frequent exacerbations) are also associated with profound long-term effects in terms of worse HRQoL, peripheral muscle weakness, reduced physical activity and exercise endurance, and poor disease prognosis $[6,26$, 40-48]. This may not be surprising considering that several studies have demonstrated that the frequency of exacerbations contributes to long-term decline in lung function of patients with COPD [6, 49-51]. However, some predominantly older studies have reported little impact of exacerbations on lung function, but these studies did not define exacerbations as currently accepted and the landmark study by FLETCHER and PETO [52] only studied mild patients with relatively few events $[53,54]$. The impact of COPD exacerbations on decline in lung function is, therefore, still uncertain and the heterogeneity of COPD has been proposed as the most likely explanation for the variable susceptibility of lung function to exacerbations [55]. It has been proposed that COPD can be divided into subtypes that are dominated by either parenechymal pathology or small airways disease and that have COPD phenotypes, including exacerbation frequency and level of functional impairment, which may differ within subtypes [55].

\section{Definitions of an exacerbation}

The definition of an exacerbation by GOLD is "an acute event characterised by a worsening of the patient's respiratory symptoms that is beyond normal day-to-day variations and leads to a change in medication" [2].

Although definitions of exacerbations often vary between clinical studies, they are usually based upon clinical presentation (severity of the symptoms) and/or healthcare resource utilisation $[2,56]$. Recent pivotal studies, e.g. the Understanding Potential Long-Term Impacts on Function with Tiotropium (UPLIFT) study in 2008, define exacerbations as an increase or new onset of at least one respiratory symptom (cough, sputum, sputum purulence, wheezing or dyspnoea) for $\geqslant 3$ days [12]. It is generally considered that moderate exacerbations are those requiring treatment with systemic glucocorticoids and/or antibiotics, while severe exacerbations are those that require hospitalisation $[11,57]$. In the clinical studies evaluated in this review, most definitions are based on a worsening of symptoms that required additional treatment with systemic glucocorticoids and/or antibiotics, or that required hospitalisation (table 1) [11, 12, 14].

Although there are many reasons why results cannot be directly compared across clinical studies, the absence of a consistent definition for exacerbations has been a major limitation to cross-study interpretation [56, 58]. This has led to the development and validation of the Chronic Pulmonary Disease-Patient Reported Outcomes (EXACT-PRO) tool, a 14item questionnaire that aims to provide a standardised method of defining and reporting exacerbations based on symptoms, which is currently undergoing validation [59].

\section{EFFECT OF BRONCHODILATORS ON EXACERBATIONS IN COPD}

As mentioned previously, inhaled long-acting bronchodilators are central to the management of COPD and are effective at reducing symptoms and preventing further exacerbations $[2,9$, $11,12,14]$. Currently available LABAs include salmeterol and formoterol (administered twice daily) and indacaterol (once daily), and the LAMA tiotropium (once daily). However, new long-acting agents are in development, including LABA and LAMA combination therapies. Both classes of bronchodilator act by relaxing airway smooth muscle tone. LABAs stimulate $\beta_{2}$-adrenergic receptors and provide functional antagonism to bronchoconstriction, whereas LAMAs prevent acetylcholine binding to muscarinic receptors that are involved in smooth muscle contractions [60]. The resulting bronchodilation leads to increased functional or inspiratory lung capacity (with lung deflation), lessening the dyspnoea and the limitations placed upon patients' ability to undertake everyday activities [11, 12, 61-63].

In terms of preventing COPD exacerbations, data for current twice-daily LABAs are mixed. To date, evidence from formoterol studies indicates that this agent has no significant benefit on moderate and severe exacerbations [10, 64-66]. In contrast, efficacy data for salmeterol has shown a beneficial effect in most, but not all studies [67, 68]. In the large, 3-yr 
TABLE 1 Clinical improvement in lung function and exacerbations in recent major clinical trials

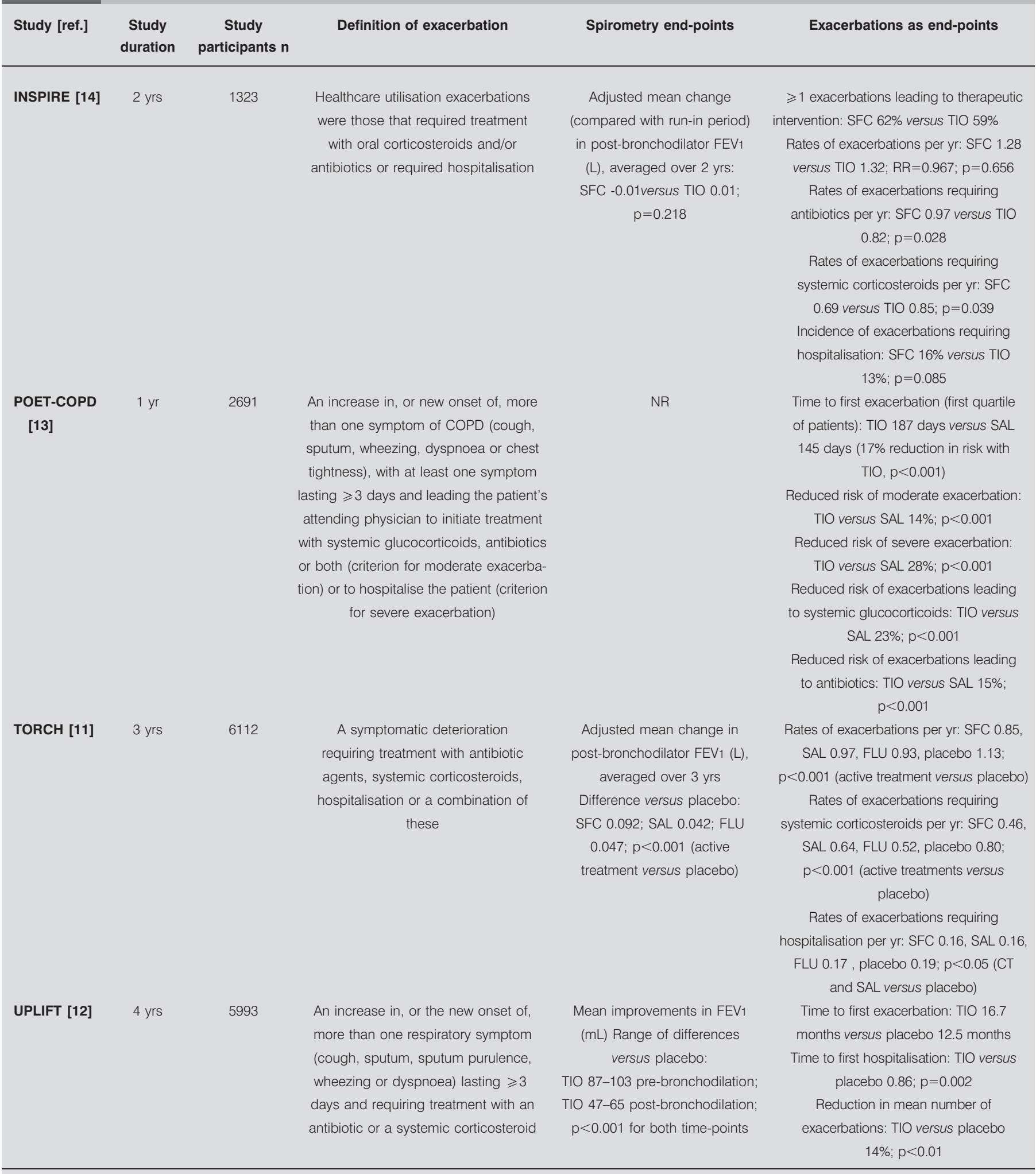

INSPIRE: Investigating New Standards for Prophylaxis in Reduction of Exacerbations; POET: Prevention of Exacerbations with Tiotropium; COPD: chronic obstructive pulmonary disease; TORCH: TOwards a Revolution in COPD Health; UPLIFT: Understanding Potential Long-Term Impacts on Function with Tiotropium; FEV1: forced expiratory volume in $1 \mathrm{~S}$; SFC: salmeterol and fluticasone propionate; TIO: tiotropium $18 \mu \mathrm{g}$ once daily; NR: not recorded; SAL: salmeterol $50 \mu \mathrm{g}$ twice daily; FLU: fluticasone propionate $500 \mu \mathrm{g}$ twice daily; CT: combination therapy. 
TORCH (Towards a Revolution in COPD Health) study $(n=6,112)$, which had greater statistical power than previous salmeterol/formoterol studies, salmeterol significantly reduced the annual rate of exacerbations, exacerbations requiring treatment with systemic corticosteroids and exacerbations requiring hospitalisation compared with placebo $(\mathrm{p}<0.05$ for all) (table 1$)$ [11]. It should be noted that none of the aforementioned formoterol and salmeterol studies were specifically designed to examine exacerbation rate.

Early clinical studies of the once-daily LAMA tiotropium demonstrated increased efficacy compared with placebo and/ or salmeterol in preventing moderate and severe COPD exacerbations and exacerbation-related hospitalisations, and lengthening the time to first COPD exacerbation [69, 70]. However, in these studies, exacerbation data were collected as adverse events. In response to these preliminary findings, two placebo-controlled clinical studies were specifically designed to prospectively test the hypothesis that tiotropium reduces exacerbations in patients with COPD $[46,71]$. In these studies, both of which involved $>1,000$ patients, tiotropium significantly reduced the proportion of patients with at least one COPD exacerbations over 6 months $(p=0.037)[46]$ and 1 yr $(p<0.01)$ [71]. Time to first exacerbation was significantly extended in the 6-month $(p=0.028)$ [46] and 1-yr study $(p<0.001)$ [71]. While the 1-yr study was not powered to detect a reduction in exacerbation-related hospitalisations [71], exacerbation-related hospitalisation was a primary end-point in the 6-month study, during which the proportion of patients with at least one exacerbation-related hospitalisation tended to decrease with tiotropium $(p=0.056)$, and time to first exacerbation-related hospitalisation tended to increase $(\mathrm{p}=0.055)$ [46]

More recently, the 4-yr UPLIFT trial evaluated the effect of tiotropium on the rate of decline in mean forced expiratory volume in $1 \mathrm{~s}$ (FEV1), as well as exacerbations [12]. In this large study, 5,993 patients with moderate-to-severe COPD received tiotropium or placebo in addition to their usual treatment. Although tiotropium did not significantly reduce the rate of decline in lung function, time to first exacerbation, time to first hospitalisation for exacerbations and mean number of exacerbations were all significantly improved compared with placebo (table 1) [12]. In a pre-specified sub-set analysis of patients from the UPLIFT study with GOLD stage II COPD, tiotropium improved exacerbation rate, time to first exacerbation and hospitalisation for exacerbation [61].

Clinical studies of the once-daily LABA indacaterol also show that it has increased efficacy versus placebo in preventing exacerbations. In the recent Indacaterol versus Tiotropium to Help Achieve New COPD Treatment Excellence (INHANCE) study, $150 \mu \mathrm{g}$ of indacaterol significantly reduced the time to first COPD exacerbation (HR 0.69, $\mathrm{p}=0.019$ ) and the rate of COPD exacerbations (rate ratio 0.67 versus placebo, $\mathrm{p}=0.044$ ) versus placebo [72]. Furthermore, the twice-daily LAMA aclidinium and once-daily LAMA NVA237 (glycopyrronium), which are in development for COPD, have demonstrated increased efficacy versus placebo in preventing moderate and severe exacerbations [73-75]. In the phase III Aclidinium To Treat Airway obstruction In COPD Patients (ATTAIN) study, the rate of exacerbations of any severity was significantly lower with $200 \mu \mathrm{g}$ and $400 \mu \mathrm{g}$ of aclidinium versus placebo (rate ratio with $200 \mu \mathrm{g}$ of aclidinium was 0.72 versus placebo $(\mathrm{p}<0.05)$ and $0.67(\mathrm{p}<0.05)$ with $400 \mu \mathrm{g}$ of aclidinium versus placebo). The frequency of moderate or severe exacerbations was also lower for aclidinium $200 \mu \mathrm{g}$ and $400 \mu \mathrm{g}$ versus placebo, although the rate ratios did not reach statistical significance $(0.74(p=0.08)$ and $0.72(p=0.06)$, respectively) [74]. In the recently completed phase III GLOW1 study, $50 \mu \mathrm{g}$ of NVA237 significantly decreased the risk of a moderate-to-severe COPD exacerbation by $31 \%(p=0.023)$ [73].

Time to first exacerbation is considered the most robust way to measure exacerbations in clinical studies [57]. This end-point is unlikely to be affected by early discontinuations and associated missing data [57], which is generally considered a limitation for most studies in COPD, including the TORCH and UPLIFT studies [76]. Furthermore, the data distribution is generally less skewed than for the annual number of exacerbations, and it is less affected by patients who have a disproportionately high number of exacerbations. However, in many studies exacerbations are secondary outcomes, and the studies are not designed in the optimal way to examine effect of treatment on exacerbations. The Prevention of Exacerbations with Tiotropium (POET)COPD study was specifically designed to compare the effects of a LAMA (tiotropium) and LABA (salmeterol) on the risk of exacerbations [13]. The results of this study showed that oncedaily tiotropium was superior to twice-daily salmeterol in prolonging the time to first exacerbation, and reduced the risk of an exacerbation by $17 \%$ (table 1 ). However, once-daily LABAs such as indacaterol are now becoming available in Europe, and there is some clinical evidence that outcomes with indacaterol are similar to those with tiotropium [72, 77]; this is being investigated further in an ongoing phase III study comparing the effects of indacaterol and tiotropium on exacerbations (www.clinicaltrials.gov identifier: NCT00845728).

Recommendations for the use of ICS in COPD centre on their effectiveness in patients with frequent exacerbations $(\geqslant 2$ per year), severe airflow limitation (GOLD stage 3 or 4 defined as FEV $1 \leqslant 30 \%$ or $<50 \%$ of predicted, or $<30 \%$ predicted, respectively), and significant health status impairment based on modified British Medical Research Council or COPD Assessment Test score [2]. Combinations of LABA plus ICS (salmeterol/ fluticasone and formoterol/budesonide) have been shown to significantly reduce exacerbation frequency in patients with COPD to a greater extent than using a LABA or ICS alone ( $p<0.05$ for all comparisons) $[10,65,67]$. However, in the INSPIRE (Investigating New Standards for Prophylaxis in Reduction of Exacerbations) study (table 1) that compared LABA plus ICS (salmeterol/fluticasone propionate) with tiotropium, overall exacerbation rates were similar [14]. Comparing the two treatments in this study, exacerbations requiring systemic corticosteroids occurred less frequently in patients receiving salmeterol/ fluticasone propionate than in those receiving tiotropium, while those requiring antibiotics were less frequent in the tiotropiumtreated patients than in those receiving salmeterol/fluticasone propionate (both $\mathrm{p}<0.05$ ) [14]. This suggests that the two treatments exerted their effects on exacerbations via different mechanisms, and raises the possibility that the different drug classes of bronchodilator are affecting exacerbations (or types of exacerbations) in different ways; these differences may also reflect the anti-inflammatory effects of the ICS component [14]. For example, sputum eosinophilia is associated with corticosteroid 
responsiveness, whereas an exacerbation characterised by high bacterial load will have a favourable response to antibiotics [38].

Bacteria-associated and sputum eosinophil-associated exacerbations rarely coexist and, because they are repeatable in patients with multiple exacerbations, they can be predicted from the stable state [38]; thus, it may be possible, and appropriate, to provide targeted tiotropium monotherapy in patients with bacteria-associated exacerbations, and combined bronchodilator/ICS therapy in patients with sputum eosinophil-dependent exacerbations. Furthermore, COPD exacerbations that begin with bacterial symptoms (sputum purulence) are more likely to have sudden, rather than gradual, onset [29], suggesting that sudden onset exacerbations may be preferentially preventable with bronchodilators, whereas gradual onset exacerbations may require the addition of corticosteroid therapy.

\section{POTENTIAL MECHANISMS FOR PREVENTING EXACERBATIONS}

Since most exacerbations are considered to be of infectious aetiology, leading to increased small airway inflammation, the mechanisms by which long-acting bronchodilators prevent exacerbations are unclear $[46,78]$. The mechanical effects of an exacerbation are shown in figure 2 . Bronchodilators may act by re-setting the threshold of lung function/dynamics (endexpiratory lung volume (EELV) and residual volume) at which an exacerbation is triggered. Improvements in resting inspiratory capacity (IC) have been shown to occur as a result of treatment with all classes of bronchodilators [3]. Increases in IC after bronchodilator therapies, which signify a reduction in EELV, result in a reduced work and oxygen cost of breathing [79]. This lung deflation primarily reflects an improvement in a)

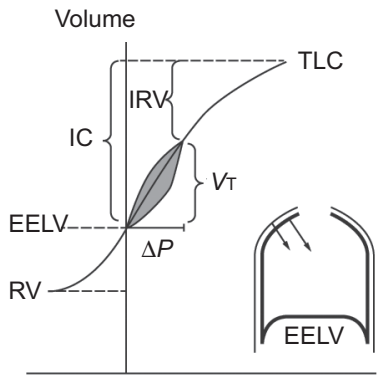

Pressure b)

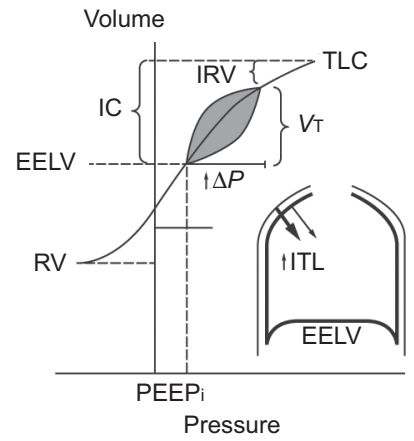

FIGURE 2. Schematic diagram of the mechanical effects of chronic obstructive pulmonary disease (COPD) exacerbation. Representative pressurevolume plots during a) stable COPD and b) COPD exacerbation. During exacerbation, worsening airflow limitation results in dynamic hyperinflation with increased end expiratory lung volume (EELV) and residual volume (RV). Corresponding reductions occur in inspiratory capacity (IC) and inspiratory reserve volume (IRV). Total lung capacity (TLC) is unchanged. As a result, tidal breathing is shifted right on the pressure-volume curve, closer to TLC. Mechanically, increased pressures must be generated to maintain tidal volume (VT). At EELV during exacerbation, intrapulmonary pressures do not return to zero, representing the development of intrinsic positive and expiratory pressure (PEEPi) which imposes increased inspiratory threshold loading (ITL) on the inspiratory muscles (inset). During the subsequent respiratory cycle, PEEPi must first be overcome in order to generate inspiratory flow. $\Delta P$ : pressure change. Reproduced from [4] mechanical lung emptying (i.e. reduced airway resistance) and increased functional strength of the inspiratory muscles, rather than increasing the static elastic recoil of the lung [3, 79]. Increased IC at rest is an important element in the decrease in dynamic EELV during exercise that occurs with bronchodilator treatment, compared with placebo [3].

The reduction in exacerbations during treatment with longacting bronchodilators may be explained, in part, by sustained bronchodilation and the consequent improvement in airflow and reduction in lung hyperinflation, resulting in a reduction in dyspnoea [13, 71, 78], Reduced lung hyperinflation has been demonstrated with bronchodilators during rest and exercise, leading to increased exercise endurance time [79-83]. Reduction in lung hyperinflation during exacerbations may lessen the ventilation/perfusion imbalance, so that patients may be less vulnerable to triggers of exacerbations [84]. Indeed, improvement in hyperinflation correlates better with improvements in exacerbation frequency than FEV1 [85].

It is possible that, in addition to bronchodilator effects and resultant reductions in lung hyperinflation, long-acting bronchodilators may also have direct or indirect effects on lung inflammation but, to date, there is little clinical evidence that LABAs or LAMAs are directly associated with improvement in airway or systemic inflammation [86]. It has been suggested that the INSPIRE study finding that tiotropium resulted in similar reductions in exacerbation rates compared with combination salmeterol/fluticasone propionate [14], which has been associated with reduced lung inflammation in COPD [87], indicates that tiotropium may also have an anti-inflammatory effect [87]. Evidence for an anti-inflammatory effect of combination therapy came from bronchial biopsies, whereas sputum analysis revealed little evidence of an anti-inflammatory effect [85, 86]. Combination therapy was associated with significant reductions in CD8+, CD4+ and CD6+ cells in bronchial biopsies. In sputum, there was no significant reduction in interleukin (IL)-8 or eosinophilic cationic protein, and a small but significant decrease in the proportion of sputum neutrophils and eosinophils.

Muscarinic receptor activation appears to have pro-inflammatory effects in a variety of cells, and in vitro studies have demonstrated that tiotropium exhibits an anti-inflammatory effect, including inhibition of acetylcholine-induced release of leukotriene (LT) $B_{4}$ from human isolated lung alveolar macrophages and A549 cells [88], regulation of CD4+ and CD8+ apoptosis of peripheral blood T-cells from patients with COPD [89], and inhibition of the pro-inflammatory effects of acetylcholine in neutrophils isolated from patients with COPD [90]. Such findings do suggest that LAMAs are capable of exerting antiinflammatory effects, as well as bronchodilator effects [85]; however, this is currently not supported by in vivo studies in COPD. In a study directly evaluating the effect of tiotropium on exacerbations in COPD and associated inflammatory markers in sputum and in serum, a $52 \%$ reduction in exacerbation frequency was observed, but there was no corresponding significant change in IL-6 or myeloperoxidase (as evidence of the presence of neutrophils), although it is possible that measurement of sputum cytokines is not the optimal means of assessing airway inflammation [86]. In this study, change in $\mathrm{LTB}_{4}$ or transforming growth factor- $\beta$, which may be more relevant to cholinergic effects, were not measured. Additionally, 
the measurements of inflammatory markers were made on sputum and airway secretions and, therefore, might not reflect changes in bronchial mucosa $[85,91]$. The LABAs salmeterol and formoterol also elicit an anti-inflammatory effect on cells. Both LABAs have been shown to decrease neutrophil recruitment, activation and function in vitro; however, the relevance of these findings to COPD patients is unclear [92]. Further investigations into inflammatory mechanisms of LABAs and LAMAs are warranted and, in particular, appropriate inflammatory markers should be measured in lung biopsies [87].

In COPD, mucus hypersecretion may contribute to airflow obstruction and increase the risk of pulmonary infection [85, 91]. It has been speculated that extended bronchodilation from tiotropium might reduce infection rates by improving clearance of respiratory secretions, such as sputum production during exacerbations, which in turn improves lung defence mechanisms [46]. As with the putative anti-inflammatory effect of long-acting bronchodilators, clinical trials have yet to convincingly demonstrate a reduction in mucus output with these agents in patients with COPD [85].

Given that viral infection is an important trigger of COPD exacerbation, preliminary evidence suggesting that tiotropium can inhibit viral activity in the lung $[93,94]$ may be relevant in relation to tiotropium-induced reductions in COPD exacerbation rates [85]. Viral inflammation-induced changes in neuronal M2 receptors have been shown to be associated with enhanced acetylcholine release in animal models of asthma [95] and, although the neuronal M2 receptor appears normal in patients with stable COPD, this has not been investigated in patients with viral-induced exacerbations [85].

Bronchodilators have been described as the pharmacological equivalent of lung volume reduction surgery (LVRS) [79]. The National Emphysema Treatment Trial showed that LVRS achieved significant improvements in exacerbation frequency and time to first exacerbation [96]. The effect on exacerbations could be attributed to a quite modest bronchodilator effect and those patients with the largest post-operative improvement in FEV1 had a significantly longer time to first exacerbation (fig. 3). Indeed, the same mechanical principle in LVRS, i.e. stabilisation of the airways and reduction of air trapping, may explain the reduction of exacerbations observed with tiotropium [97]. Significant correlations between changes in FEV1 and exacerbation frequency have been demonstrated for tiotropium $(p=0.003$ ) [98]. However, in contrast to bronchodilator therapy, increased elastic lung recoil pressure and decreases in dead space-to-alveolar ventilation ratio are important mechanisms of lung deflation in LVRS $[99,100]$.

Recent studies have demonstrated that combining LAMA and LABA bronchodilators have additive effects on airway function in patients with moderate-to-severe COPD [83, 101, 102]. Therefore, if the beneficial effect of bronchodilators on exacerbations is due to reduced airway resistance, improved IC and reduced hyperinflation, which is likely, then the improved lung function that can be achieved using combined LABA and LAMA bronchodilators (versus either alone) should also confer further benefits in terms of exacerbations. However, this remains to be confirmed in appropriately designed clinical studies.

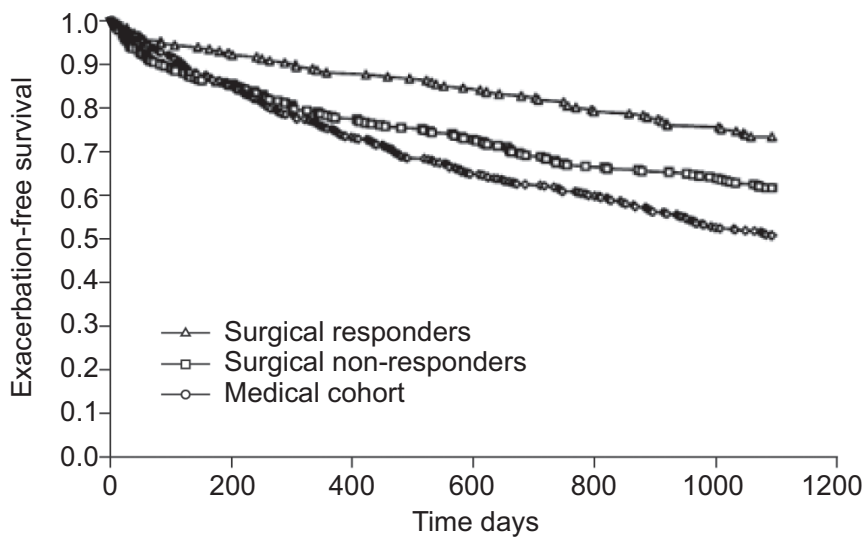

FIGURE 3. Time-to-event analysis of exacerbation-free survival in patients according to their forced expiratory volume in $1 \mathrm{~s}$ (FEV 1 ) response to lung volume reduction surgery. Surgical responders were defined as those with a 6-month improvement in FEV $1>0.2 \mathrm{~L}$ and surgical non-responders as those with an FEV 1 improvement $<0.2 \mathrm{~L}$. Reproduced from [96] with permission from the publisher

Evidence indicates that once-daily LAMAs and LABAs have superior bronchodilation and clinical efficacy over twice-daily agents, as demonstrated by the superior effect of tiotropium compared with salmeterol on exacerbation outcomes in the POET-COPD study [13]. This may simply reflect the action of a more potent bronchodilator $[103,104]$. The sustained 24-h bronchodilator effect of a once-daily bronchodilator compared with the more variable effect of a twice-daily agent may also be relevant (fig. 4) [105]. The range of long-acting bronchodilators available to treat COPD has expanded with the availability of the once-daily LABA, indacaterol, for which there is some clinical evidence that outcomes are at least as good as those with tiotropium [72, 77], Further research into the effect of bronchodilator treatment on exacerbations could usefully compare these two once-daily bronchodilators.

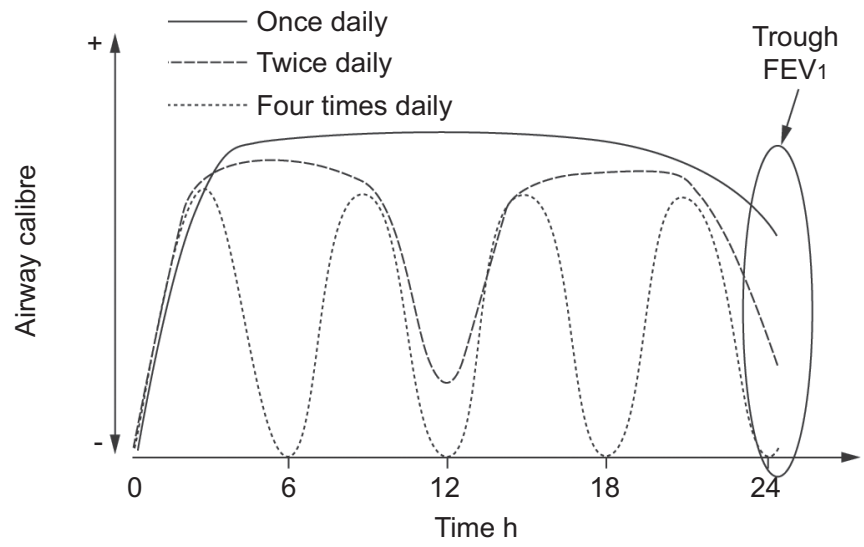

FIGURE 4. Schematic model of the effects of long-acting (once daily or twice daily) versus short-acting (four times daily) bronchodilators on 24-h airway tone (pharmacological stenting). With extended duration of bronchodilation, the net area under the time/airflow curve increases, and persistent bronchorelaxant effects of once-daily and twice-daily bronchodilators lead to increased morning forced expiratory volume in $1 \mathrm{~s}$ (FEV 1 ) following the last inhalation (trough FEV1). Reproduced from [105]. 


\section{CONCLUSIONS}

Exacerbations are a critical outcome measure in COPD that are associated with poor HRQoL, place a greater burden on the healthcare service and, ultimately, shorten survival. There is a large body of clinical evidence showing that long-acting bronchodilators are effective in preventing both moderate and severe exacerbations. Although various mechanisms are likely to be involved in the effect of bronchodilators on exacerbations, the most important probably involves reduction of hyperinflation and a re-setting of lung function dynamics. It is possible that future developments in bronchodilator treatments will further improve the efficacy of these agents on this critically important feature of COPD.

\section{SUPPORT STATEMENT}

Writing and editorial assistance was funded by Novartis Pharma AG (Basel, Switzerland).

\section{STATEMENT OF INTEREST}

Statements of interest for all authors and the study itself can be found at www.erj.ersjournals.com/site/misc/statements.xhtml

\section{ACKNOWLEDGEMENTS}

Writing and editorial assistance was provided by C. Chinn, S. Filcek, M. Stephens (Circle Science, Macclesfield, UK) and M. Fedele (Novartis, East Hanover, NJ, USA). This assistance was funded by Novartis Pharma AG (Basel, Switzerland).

\section{REFERENCES}

1 World Health Organization. Chronic respiratory diseases. Burden of chronic respiratory diseases. www.who.int/respiratory/copd/ burden/en/index.html Date last accessed: March 19, 2012.

2 Global Initiative for Chronic Obstructive Lung Disease. Global Strategy for the Diagnosis, Management and Prevention of chronic obstructive pulmonary disease. Revised 2011. www. goldcopd.org Date last updated: December 2011. Date last accessed: March 19, 2012.

3 O'Donnell DE, Laveneziana P. The clinical importance of dynamic lung hyperinflation in COPD. COPD 2006; 3: 219-232.

4 O'Donnell DE, Parker CM. COPD exacerbations. 3: Pathophysiology. Thorax 2006; 61: 354-361.

5 Wedzicha JA, Seemungal TA. COPD exacerbations: defining their cause and prevention. Lancet 2007; 370: 786-796.

6 Donaldson GC, Seemungal TA, Bhowmik A, et al. Relationship between exacerbation frequency and lung function decline in chronic obstructive pulmonary disease. Thorax 2002; 57: 847-852.

7 Anzueto A. Impact of exacerbations on COPD. Eur Respir Rev 2010; 19: 113-118.

8 O'Brien JA, Ward AJ, Jones MK, et al. Utilization of health care services by patients with chronic obstructive pulmonary disease. Respir Med 2003; 97: Suppl. A, S53-S58.

9 National Institute for Health and Clinical Excellence (NICE). Chronic obstructive pulmonary disease: management of chronic obstructive pulmonary disease in adults in primary and secondary care. 2010. http://guidance.nice.org.uk/CG101/ Guidance/pdf/English Date last updated: October 2011. Date last accessed: March 19, 2012.

10 Calverley PM, Boonsawat W, Cseke Z, et al. Maintenance therapy with budesonide and formoterol in chronic obstructive pulmonary disease. Eur Respir J 2003; 22: 912-919.

11 Calverley PM, Anderson JA, Celli B, et al. Salmeterol and fluticasone propionate and survival in chronic obstructive pulmonary disease. N Engl J Med 2007; 356: 775-789.
12 Tashkin DP, Celli B, Senn S, et al. A 4-year trial of tiotropium in chronic obstructive pulmonary disease. N Engl J Med 2008; 359: 1543-1554.

13 Vogelmeier C, Hederer B, Glaab T, et al. Tiotropium versus salmeterol for the prevention of exacerbations of COPD. N Engl J Med 2011; 364: 1093-1103.

14 Wedzicha JA, Calverley PM, Seemungal TA, et al. The prevention of chronic obstructive pulmonary disease exacerbations by salmeterol/fluticasone propionate or tiotropium bromide. Am J Respir Crit Care Med 2008; 177: 19-26.

15 Rabe KF. Treating COPD - the TORCH trial, $\mathrm{p}$ values, and the Dodo. N Engl J Med 2007; 356: 851-854.

16 Bhowmik A, Seemungal TA, Sapsford RJ, et al. Relation of sputum inflammatory markers to symptoms and lung function changes in COPD exacerbations. Thorax 2000; 55: 114-120.

17 Celli B, ZuWallack R, Wang S, et al. Improvement in resting inspiratory capacity and hyperinflation with tiotropium in COPD patients with increased static lung volumes. Chest 2003; 124: 1743-1748.

18 Qiu Y, Zhu J, Bandi V, et al. Biopsy neutrophilia, neutrophil chemokine and receptor gene expression in severe exacerbations of chronic obstructive pulmonary disease. Am J Respir Crit Care Med 2003; 168: 968-975.

19 Wilkinson TM, Hurst JR, Perera WR, et al. Effect of interactions between lower airway bacterial and rhinoviral infection in exacerbations of COPD. Chest 2006; 129: 317-324.

20 Celli BR, Barnes PJ. Exacerbations of chronic obstructive pulmonary disease. Eur Respir J 2007; 29: 1224-1238.

21 Seemungal T, Harper-Owen R, Bhowmik A, et al. Respiratory viruses, symptoms, and inflammatory markers in acute exacerbations and stable chronic obstructive pulmonary disease. Am J Respir Crit Care Med 2001; 164: 1618-1623.

22 Sethi S, Evans N, Grant BJ, et al. New strains of bacteria and exacerbations of chronic obstructive pulmonary disease. $N$ Engl J Med 2002; 347: 465-471.

23 Papi A, Bellettato CM, Braccioni F, et al. Infections and airway inflammation in chronic obstructive pulmonary disease severe exacerbations. Am J Respir Crit Care Med 2006; 173: 1114-1121.

24 Hurst JR, Vestbo J, Anzueto A, et al. Susceptibility to exacerbation in chronic obstructive pulmonary disease. $N$ Engl J Med 2010; 363: 1128-1138.

25 Quint JK, Donaldson GC, Hurst JR, et al. Predictive accuracy of patient-reported exacerbation frequency in COPD. Eur Respir J 2011; 37: 501-507.

26 Seemungal TA, Donaldson GC, Paul EA, et al. Effect of exacerbation on quality of life in patients with chronic obstructive pulmonary disease. Am J Respir Crit Care Med 1998; 157: 1418-1422.

27 Hurst JR, Donaldson GC, Quint JK, et al. Temporal clustering of exacerbations in chronic obstructive pulmonary disease. Am J Respir Crit Care Med 2009; 179: 369-374.

28 Perera WR, Hurst JR, Wilkinson TM, et al. Inflammatory changes, recovery and recurrence at COPD exacerbation. Eur Respir J 2007; 29: 527-534.

29 Aaron SD, Donaldson GC, Whitmore GA, et al. Time course and pattern of COPD exacerbation onset. Thorax 2012; 67: 238-243.

30 Langsetmo L, Platt RW, Ernst P, et al. Underreporting exacerbation of chronic obstructive pulmonary disease in a longitudinal cohort. Am J Respir Crit Care Med 2008; 177: 396-401.

31 Wilkinson TM, Donaldson GC, Hurst JR, et al. Early therapy improves outcomes of exacerbations of chronic obstructive pulmonary disease. Am J Respir Crit Care Med 2004; 169: 1298-1303.

32 Barbera JA, Roca J, Ferrer A, et al. Mechanisms of worsening gas exchange during acute exacerbations of chronic obstructive pulmonary disease. Eur Respir J 1997; 10: 1285-1291. 
33 Casadevall C, Coronell C, Ramirez-Sarmiento AL, et al. Upregulation of pro-inflammatory cytokines in the intercostal muscles of COPD patients. Eur Respir J 2007; 30: 701-701.

34 Hogg JC, Chu F, Utokaparch S, et al. The nature of small-airway obstruction in chronic obstructive pulmonary disease. $N$ Engl Med 2004; 350: 2645-2653.

35 Wedzicha JA, Hurst JR. Structural and functional co-conspirators in chronic obstructive pulmonary disease exacerbations. Proc Am Thorac Soc 2007; 4: 602-605.

36 Saha S, Brightling CE. Eosinophilic airway inflammation in COPD. Int J Chron Obstruct Pulmon Dis 2006; 1: 39-47.

37 Siva R, Green RH, Brightling CE, et al. Eosinophilic airway inflammation and exacerbations of COPD: a randomised controlled trial. Eur Respir J 2007; 29: 906-913.

38 Bafadhel M, McKenna S, Terry S, et al. Acute exacerbations of chronic obstructive pulmonary disease: identification of biologic clusters and their biomarkers. Am J Respir Crit Care Med 2011; 184: 662-671.

39 Hoogendoorn M, Hoogenveen RT, Rutten-van Molken MP, et al Case fatality of COPD exacerbations: a meta-analysis and statistical modelling approach. Eur Respir J 2011; 37: 508-515.

40 Donaldson GC, Seemungal TA, Patel IS, et al. Airway and systemic inflammation and decline in lung function in patients with COPD. Chest 2005; 128: 1995-2004.

41 Soler-Cataluna JJ, Martinez-Garcia MA, Roman Sanchez P, et al. Severe acute exacerbations and mortality in patients with chronic obstructive pulmonary disease. Thorax 2005; 60: 925-931.

42 Miravitlles M, Ferrer M, Pont A, et al. Effect of exacerbations on quality of life in patients with chronic obstructive pulmonary disease: a 2 year follow up study. Thorax 2004; 59: 387-395.

43 Bernard S, LeBlanc P, Whittom F, et al. Peripheral muscle weakness in patients with chronic obstructive pulmonary disease. Am J Respir Crit Care Med 1998; 158: 629-634.

44 Cazzola M, MacNee W, Martinez FJ, et al. Outcomes for COPD pharmacological trials: from lung function to biomarkers. Eur Respir J 2008; 31: 416-469.

45 Mannino DM, Watt G, Hole D, et al. The natural history of chronic obstructive pulmonary disease. Eur Respir J 2006; 27: 627-643.

46 Niewoehner DE, Rice K, Cote C, et al. Prevention of exacerbations of chronic obstructive pulmonary disease with tiotropium, a once-daily inhaled anticholinergic bronchodilator: a randomized trial. Ann Intern Med 2005; 143: 317-326.

47 Spruit MA, Gosselink R, Troosters T, et al. Muscle force during an acute exacerbation in hospitalised patients with COPD and its relationship with CXCL8 and IGF-I. Thorax 2003; 58: 752-756.

48 Wedzicha JA, Donaldson GC. Exacerbations of chronic obstructive pulmonary disease. Respir Care 2003; 48: 1204-1213.

49 Kanner RE, Anthonisen NR, Connett JE. Lower respiratory illnesses promote $\mathrm{FEV}(1)$ decline in current smokers but not exsmokers with mild chronic obstructive pulmonary disease: results from the lung health study. Am I Respir Crit Care Med 2001; 164: 358-364

50 Vestbo J, Edwards LD, Scanlon PD, et al. Changes in forced expiratory volume in 1 second over time in COPD. $N$ Engl J Med 2011; 365: 1184-1192.

51 Seemungal TA, Donaldson GC, Bhowmik A, et al. Time course and recovery of exacerbations in patients with chronic obstructive pulmonary disease. Am J Respir Crit Care Med 2000; 161 1608-1613.

52 Fletcher C, Peto R. The natural history of chronic airflow obstruction. BMJ 1977; 1: 1645-1648.

53 Howard P. Long-term follow-up of respiratory symptoms and ventilatory function in a group of working men. $\mathrm{Br} J$ Ind Med 1970; 27: 326-333.

54 Bates DV. The fate of the chronic bronchitic: a report of the tenyear follow-up in the Canadian Department of Veteran's Affairs coordinated study of chronic bronchitis. The J. Burns Amberson Lecture of the American Thoracic Society. Am Rev Respir Dis 1973; 108: 1043-1065.

55 Silverman EK. Exacerbations in chronic obstructive pulmonary disease: do they contribute to disease progression? Proc Am Thorac Soc 2007; 4: 586-590.

56 Effing TW, Kerstjens HA, Monninkhof EM, et al. Definitions of exacerbations: does it really matter in clinical trials on COPD? Chest 2009; 136: 918-923.

57 Beeh KM, Hederer B, Glaab T, et al. Study design considerations in a large COPD trial comparing effects of tiotropium with salmeterol on exacerbations. Int J Chron Obstruct Pulmon Dis 2009; 4: 119-125.

58 Aaron SD, Fergusson D, Marks GB, et al. Counting, analysing and reporting exacerbations of COPD in randomised controlled trials. Thorax 2008; 63: 122-128.

59 Leidy NK, Wilcox TK, Jones PW, et al. Standardizing measurement of chronic obstructive pulmonary disease exacerbations. Reliability and validity of a patient-reported diary. Am J Respir Crit Care Med 2011; 183: 323-329.

60 Barnes PJ. Distribution of receptor targets in the lung. Proc Am Thorac Soc 2004; 1: 345-351.

61 Decramer M, Celli B, Kesten S, et al. Effect of tiotropium on outcomes in patients with moderate chronic obstructive pulmonary disease (UPLIFT): a prespecified subgroup analysis of a randomised controlled trial. Lancet 2009; 374: 1171-1178.

62 Hanania NA, Sharafkhaneh A, Celli B, et al. Acute bronchodilator responsiveness and health outcomes in COPD patients in the UPLIFT trial. Respir Res 2011; 12: 6

63 O'Donnell DE, Webb KA. The major limitation to exercise performance in COPD is dynamic hyperinflation. J Appl Physiol 2008; 105: 753-755

64 Rennard SI, Tashkin DP, McElhattan J, et al. Efficacy and tolerability of budesonide/formoterol in one hydrofluoroalkane pressurized metered-dose inhaler in patients with chronic obstructive pulmonary disease: results from a 1-year randomized controlled clinical trial. Drugs 2009; 69: 549-565.

65 Szafranski W, Cukier A, Ramirez A, et al. Efficacy and safety of budesonide/formoterol in the management of chronic obstructive pulmonary disease. Eur Respir J 2003; 21: 74-81.

66 Vogelmeier C, Kardos P, Harari S, et al. Formoterol mono- and combination therapy with tiotropium in patients with COPD: a 6-month study. Respir Med 2008; 102: 1511-1520.

67 Calverley P, Pauwels R, Vestbo J, et al. Combined salmeterol and fluticasone in the treatment of chronic obstructive pulmonary disease: a randomised controlled trial. Lancet 2003; 361: 449-456.

68 Stockley RA, Chopra N, Rice L. Addition of salmeterol to existing treatment in patients with COPD: a 12 month study. Thorax 2006; 61: 122-128.

69 Brusasco V, Hodder R, Miravitlles M, et al. Health outcomes following treatment for 6 months with once daily tiotropium compared with twice daily salmeterol in patients with COPD. Thorax 2003; 58: 399-404.

70 Casaburi R, Mahler DA, Jones PW, et al. A long-term evaluation of once-daily inhaled tiotropium in chronic obstructive pulmonary disease. Eur Respir J 2002; 19: 217-224.

71 Dusser D, Bravo M-L, Iacono P. The effect of tiotropium on exacerbations and airflow in patients with COPD. Eur Respir J 2006; 27: 547-555.

72 Donohue JF, Fogarty C, Lotvall J, et al. Once-daily bronchodilators for chronic obstructive pulmonary disease: indacaterol versus tiotropium. Am J Respir Crit Care Med 2010; 182: 155-162.

73 D'Urzo A, Ferguson G, Martin C, et al. NVA237 once daily reduces the percentage of patients with exacerbations of COPD and associated hospitalizations: The GLOW1 trial. Eur Respir J 2011; 38: Suppl. 55, 608s. 
74 Jones PW, Singh D, Bateman ED, et al. Efficacy and safety of twice-daily aclidinium bromide in COPD patients: the ATTAIN study. Eur Respir J 2012; [Epub ahead of print DOI: 10.1183/ 09031936.00225511].

75 Kerwin E, Hébert J, Gallagher N, et al. Efficacy and safety of NVA237 versus placebo and tiotropium in patients with moderateto-severe COPD over 52 weeks: the GLOW2 study. Eur Respir J 2012; [Epub ahead of print DOI: 10.1183/09031936.00040712].

76 Niewoehner DE. TORCH and UPLIFT: what has been learned from the COPD "mega-trials"? COPD 2009; 6: 1-3.

77 Buhl R, Dunn LJ, Disdier C, et al. Blinded 12-week comparison of once-daily indacaterol and tiotropium in COPD. Eur Respir J 2011; 38: 797-803.

78 Tashkin DP. Preventing and managing exacerbations in COPD critical appraisal of the role of tiotropium. Int J Chron Obstruct Pulmon Dis 2010; 5: 41-53.

79 O'Donnell DE. Is sustained pharmacologic lung volume reduction now possible in COPD? Chest 2006; 129: 501-503.

80 Maltais F, Celli B, Casaburi R, et al. Aclidinium bromide improves exercise endurance and lung hyperinflation in patients with moderate to severe COPD. Respir Med 2011; 105: 580-587.

81 O'Donnell DE, Fluge T, Gerken F, et al. Effects of tiotropium on lung hyperinflation, dyspnoea and exercise tolerance in COPD. Eur Respir J 2004; 23: 832-840.

82 O'Donnell DE, Casaburi R, Vincken W, et al. Effect of indacaterol on exercise endurance and lung hyperinflation in COPD. Respir Med 2011; 105: 1030-1036.

83 van Noord JA, Aumann JL, Janssens E, et al. Effects of tiotropium with and without formoterol on airflow obstruction and resting hyperinflation in patients with COPD. Chest 2006; 129: 509-517.

84 Rodriguez-Roisin R. Impacting patient-centred outcomes in COPD: exacerbations and hospitalizations. Eur Respir Rev 2006; 15: 47-50.

85 Trevethick M, Clarke N, Strawbridge M, et al. Inhaled muscarinic antagonists for COPD - does an anti-inflammatory mechanism really play a role? Curr Opin Pharmacol 2009; 9: 250-255.

86 Powrie DJ, Wilkinson TM, Donaldson GC, et al. Effect of tiotropium on sputum and serum inflammatory markers and exacerbations in COPD. Eur Respir J 2007; 30: 472-478.

87 Barnes NN, Qui Y-S, Pavord ID, et al. Anti-inflammatory effects of salmeterol/fluticasone proprionate in chronic obstructive pulmonary disease. Am J Respir Crit Care Med 2006; 173: 736-743.

88 Buhling F, Lieder N, Kuhlmann UC, et al. Tiotropium suppresses acetylcholine-induced release of chemotactic mediators in vitro. Respir Med 2007; 101: 2386-2394.

89 Profita $\mathrm{M}$, Riccobono $\mathrm{L}$, Montalbano $\mathrm{AM}$, et al. In vitro anticholinergic drugs affect CD8+ peripheral blood T-cells apoptosis in COPD. Immunobiology 2012; 217: 345-353.
90 Profita M, Giorgi R, Sala A, et al. Muscarinic receptors, leukotriene B4 production and neutrophilic inflammation in COPD. Allergy 2005; 60: 1361-1369.

91 Bateman ED, Rennard S, Barnes PJ, et al. Alternative mechanisms for tiotropium. Pulm Pharmacol Ther 2009; 22: 533-542.

92 Johnson M, Rennard S. Alternative mechanisms for long-acting $\beta_{2}$-adrenergic agonists in COPD. Chest 2001; 120: 258-270.

93 Dicpinigaitis PV, Spinner L, Santhyadka G, et al. Effect of tiotropium on cough reflex sensitivity in acute viral cough. Lung 2008; 186: 369-374.

94 Iesato K, Tatsumi K, Saito K, et al. Tiotropium bromide attenuates respiratory syncytial virus replication in epithelial cells. Respiration 2008; 76: 434-441.

95 Fryer AD, Jacoby DD. Muscarinic receptors and the control of airway smooth muscle. Am J Respir Crit Care Med 1998; 158: S154-S160.

96 Washko GR, Fan VS, Ramsey SD, et al. The effect of lung volume reduction surgery on chronic obstructive pulmonary disease exacerbations. Am J Respir Crit Care Med 2008; 177: 164-169.

97 Miravitlles M. Prevention of exacerbations of COPD with pharmacotherapy. Eur Respir Rev 2010; 19: 119-126.

98 Anzueto A, Leimer I, Kesten S. Impact of frequency of COPD exacerbations on pulmonary function, health status and clinical outcomes. Int J Chron Obstruct Pulmon Dis 2009; 4: 245-251.

99 Ferguson GT, Fernandez E, Zamora MR, et al. Improved exercise performance following lung volume reduction surgery for emphysema. Am J Respir Crit Care Med 1998; 157: 1195-1203.

100 Sciurba FC, Rogers RM, Keenan RJ, et al. Improvement in pulmonary function and elastic recoil after lung-reduction surgery for diffuse emphysema. N Engl J Med 1996; 334: 1095-1099.

101 van Noord JA, Aumann JL, Janssens E, et al. Combining tiotropium and salmeterol in COPD: effects on airflow obstruction and symptoms. Respir Med 2010; 104: 995-1004.

102 van Noord JA, Buhl R, Laforce C, et al. QVA149 demonstrates superior bronchodilation compared with indacaterol or placebo in patients with chronic obstructive pulmonary disease. Thorax 2010; 65: 1086-1091.

103 Donohue JF, van Noord JA, Bateman ED, et al. A 6-month, placebo-controlled study comparing lung function and health status changes in COPD patients treated with tiotropium or salmeterol. Chest 2002; 122: 47-55.

104 Wedzicha JA. Choice of bronchodilator therapy for patients with COPD. N Engl J Med 2011; 364: 1167-1168.

105 Beeh KM, Beier J. The short, the long and the "ultra-long": why duration of bronchodilator action matters in chronic obstructive pulmonary disease. Adv Ther 2010; 27: 150-159. 